\title{
Challenges for science: the exploitation of deep deposits
}

\author{
Miranda Ptak $^{1,2, *}$, Paula Podolska ${ }^{1}$ and Robert Podolski ${ }^{2}$ \\ ${ }^{1}$ Wroclaw University of Science and Technology, Faculty of Geoengineering, Mining and Geology, 27 Wyb. Wyspiańskiego St., \\ 50-370 Wroclaw, Poland \\ ${ }^{2}$ District Mining Office in Wrocław, 41 Kotlarska St., 50-151 Wroclaw, Poland
}

\begin{abstract}
The article poses open invitation questions directed towards young scientists. The questions result from the analysis of condition met in deep mining, both in Poland and all around the world, based on selected examples. A conference devoted to the interdisciplinary issues related to mining and geology, gathering $\mathrm{Ph}$. D. students and young scholars is an ideal platform to inspire research and curiosity of new occurring phenomena but also to verify the directions of research on an ongoing basis. Each month, each year, brings new solutions supporting further research and development. The main topic of this paper is indication of technical and legal problems that need to be resolved as they may be a barrier to further mining operations. The aforementioned problems can be divided into those related directly to the exploitation, occupational safety, and environmental protection. The article illustrates the solutions and experiences from the entire world that should be considered during analysis and solution appropriately adjusted and introduced into execution. Exploitation of new "Glogow Gleboki Przemyslowy" (GGP) project is the primary task of KGHM for the next 10 years. Development plan requires an interdisciplinary approach. It needs to be based on worldwide experiences and the most recent technical and technological solutions as well as crucial analysis of think tanks bodies.
\end{abstract}

\section{Exploitation of deep deposits}

While discussing the issues of mining in relation of deep deposits exploitation, it is essential to explain the conditions in which it takes place as a part of definition. It was assumed that for copper deposit these are geological and mining conditions below $1200 \mathrm{~m}$. Although this is an arbitrarily adopted parameter and it must be considered that the definition of a deep mine is far more complex. For example, the climatic conditions occurring at the level of $1200 \mathrm{~m}$ of Polish copper mines because of their extensive structures are equal to the conditions of gold mines in RPA, approximately $3000 \mathrm{~m}$ deep. Managing the problems related to the exploitation of deep mineral deposits is a challenge to all countries relying on strong raw minerals economy. Strategic resources such as copper are crucial for the development of the world economy. The number of geotechnical hazards at great depths and the impact of the rock mass pressure related to them is still the main challenge for the safety and stability of the deep mines' workings. Deeper exploitation is accompanied by additional difficulties and natural hazards. Constant increase of the depth of underground operations in the Polish mining reaches 10 $\mathrm{m}$ each year. The geological and technical conditions have an influence on the safety of mining operations, especially when combined with numerous natural hazards. The decreasing mineralisation of the deposits implies the necessity for more "intensive" exploitation under extremely unfavourable conditions. Despite the new policies forcing recycling of minerals worldwide consumption constantly growing. These trends demand for more raw materials, especially strategic metals causes the deeper exploitation much faster. Mining in the specific conditions requires long-term strategic planning as well as the acknowledgement of the need for periodic modernisation of the entire technological processes according to condition we encounter at the considerable depth. For that reason, new solutions are to be constantly developed, as new research areas emerge, requiring new tools and methods, as well as techniques and technologies.

\subsection{The problems of deep mining in Poland}

\subsubsection{Deep mining in Poland}

In Poland, the mining regulations set certain legal obligations for the entrepreneurs. As art.117 of Geological and Mining Law of 9th of June 2011 states „The entrepreneur is obliged to:

1) identify hazards associated with mining plant operations and have to implement the measures to prevent and remove or work against these hazards;

2) have adequate financial and technical resources, and operation services to ensure the safety of workers and mining plant;

\footnotetext{
* Corresponding author: miranda.ptak@pwr.edu.pl
} 
3) to keep records of people present in the mining plant, by indicating the name and official position;

4) evaluate and document the occupational risk and apply the necessary solutions that mitigate this risk, including the drafting of the document of the occupational health and safety;

5) to preserve and properly archive the records on the mining plant operations;

6) to possess the evidence of technical solutions verification for the mining plant by an expert on the mining plant operation - in the cases specified in the regulations issued under Art. 120 par. 1 and 2 .

According to this law, the entrepreneur should explore, document, and assess the possible dangers. Hazards and phenomena encountered in recent years in GGP deposit implies the need to change our way of thinking in many aspects and fields; organisational, technical, as well as legislative. Apart from external research services, it is also important to stimulate the creativity of the employees. The last few years in mining gave us many tough engineering lessons. A few of them were very painful and showed us areas of ignorance. They oblige us to re-evaluate many matters and regulations to anticipate risks. Our common; scientist, mining engineers, mining authority fundamental duty is to initiate researches for anticipating occurring and fighting increase of risks and hazards. The main goals now of the KGHM strategic planning in the period of minimum 10 years should be dedicated to:

- defining and assessing natural hazards,

- designing and developing ventilation and underground transportation structure,

- choice of machinery and equipment appropriate for the parameters of the deposit,

- protection of environmental conditions in the workplace,

- assuring of waste management optimisation,

- guarantee minimisation of emissions,

- water and wastewater management,

- recruitment of workers, training.

\subsubsection{Mining worldwide}

To illustrate the paper issues dedicated to deep mining in GGP deposit a group of foreign mines with similar problems that occur or may occur in mentioned area have been selected. The dissimilarity and uniqueness of Polish copper ore mines is based on their considerable dispersion of production divisions in vast underground territory comparing to the limited space of foreign mines operating in the vein deposits. Exploitation in Polish copper mines is carried out in horizontal sedimentary deposit in area of almost $400 \mathrm{~km}^{2}$. Nevertheless, always learning about and use others' experience is less expensive.

According to the authors, between 2020 and 2030 Canadian mining is to experience technical challenges of unparalleled scale, the greatest among which is maintaining efficient shaft transportation, ventilation and drainage. The last decade was marked by the increase in the number of accidents in the Ontario Province, 24 of which were fatal. The number of people employed in the mines in Ontario reaches 27,000 workers. In Canada mines are classified as a deep when reach depth below $2000 \mathrm{~m}$. In Creighton, the mining activity is being performed below $2500 \mathrm{~m}$. which classified this mine as being the very deep. The mine and its experiences are the leading model for the mines in Manitoba, Ontario, and Quebec Provinces. Among the main problems and dangers it faces are:

a) maintenance of the flexibility of technological processes and the rising requirements for the realisation of the production demands,

b) occurring of rock bursts of significant energy and increasing intensity, destroying the structure of the mine,

c) the energy consumption of the production process, mainly because of the constantly increasing costs of air cooling.

With this goal in mind, Canadians responsibly monitor their mines. In Canada, the work insurance system and additionally social lack of acceptance for accidents at work forced and led to the development of a number of effective solutions.

A In mines threatened with rock bursts, it is a modern seismoacoustic monitoring built on the registration of a full range of phenomena and algorithms (software). The network of observations and measurements of seismic activity by the microseismic method has been functioning in the Creighton mine since 1980 and is constantly being developed. The measurements are based on the work of the ESG station Hyperion 104 channel recording signals from one and three axis accelerometers. Additionally, ESG Hyperion the 24 channel apparatus registers high energy phenomena. Based on the computer analysis of the SeisWatch program allows to use preventive crew evacuation procedures based on spontaneous rock mass seismic activity and induced response after blasting works [1-4].The important issue of mining, both in Poland and worldwide, are the physical fitness problems of the mining crew. The social processes occurring in modern societies have caused the level of physical fitness to decrease. The current generation of miners are people between 40 and 50 years old, generally suffering from diabetes and being overweight. That situation induced the need to monitor constantly the health of the miners especially in hot climate conditions. The new idea to introduce the pulse monitoring of all miners population in 10 years is still in the planning phase. The realisation of this goal would allow "dose work individually". The target of the project is the creation of the proper condition in the underground workplace at depth of $3000 \mathrm{~m}$. Canadians pay a lot of attention to the specialised clothing, decreasing the central air conditioning systems expenses, and providing the best protection to the worker. Workers are to be equipped with helmets fully securing their respiratory systems from air temperature, gasses and exhaust fumes. Such equipment is already being used by Swedish fire fighters $[4,5]$.

Mining in Sweden has a long tradition of introducing modern technical and technological 
solutions. One of the most important policies in this country is the consistently implemented long-term planning especially in mining. It this country however, long term planning policy is crucial. The Kiruna mine operates on vein iron ore deposit. Mineralized zone is extended to $4 \mathrm{~km}$ and $80 \mathrm{~m}$ wide and deposits resources are documented up to $2000 \mathrm{~m}$ deep (Fig. 1). The mine has 11 shafts subjected periodically many stages of modernisation. At the early beginning of the 1990s, the Kiruna mined 25 million tons from different levels, where $775 \mathrm{~m}$. was the deepest one at the time. In that period the gradual cessation of the exploitation was being considered. Long term strategic thinking prevailed. Simultaneously, the challenges posed by exploitation at deeper levels forced progress and improvement of equipment, modern control systems of all production processes. The already leading in Swedish industry Kiruna mine became the global example of modernity. In 1998, the decision concerning opening level 1045 resulted in yearly extraction of about 27.5 million tons. In 2008, another strategic decision resulted in opening of level 1365 enable increase of iron ore output of about $25 \%$. The design and research works accompanying these processes led to the "construction of a new modern mine". The final result of the undertaking was a wide range of investments into vertical and horizontal transportation systems completed with full automation of the transport system what significantly increase its efficiency. Unpredictable rock burst manifested in 2008 has forced and resulted in numerous research works. A series of model blasts simulating very strong tremors was performed in order to verify the behaviour of the supports, its relation with the rock mass as well as to assess the safety efficiency of the mine supports. The aim was to find an adequate support to the strong dynamic stress resulting from seismic phenomenon or rockbursts. The research covered the measurement the energy of events, as well as the deformation of the rock mass and the mines supports. It indicated much higher seismic speeds than similar model blasts performed in other countries. Such tests allow for making plans with a known risk factor. It is also very important to mention that deeper exploitation provoked various forms of deformation and have compromised safety of habitants. It has had affected surface structures. The scales of the impact led to decision of reconstruction of the town in a new place and settlement structures are to be moved (Fig. 2). The first new buildings in the centre of the new Kiruna are to be built in 2019 [4, 6, 7].

Mines in South Africa [4, 8] are known as the world deepest and one of them Mponeng is a model for purpose of this presentation. Among many points at the problems related to deep mining the first challenge that begins the sequence of problems to be solved is transporting mining crews on large distances is one (Fig. $3)$.

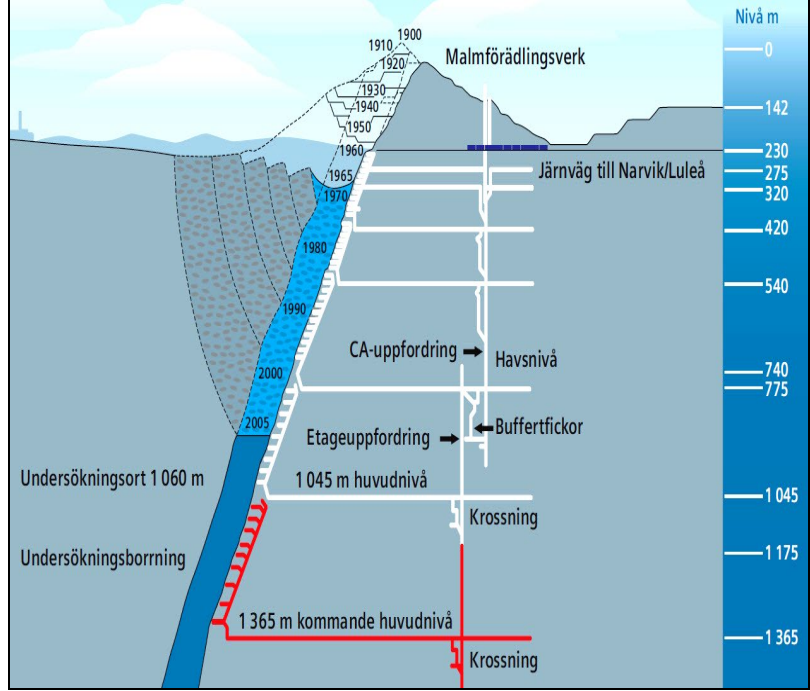

Fig. 1. The development of the Kiruna mine.

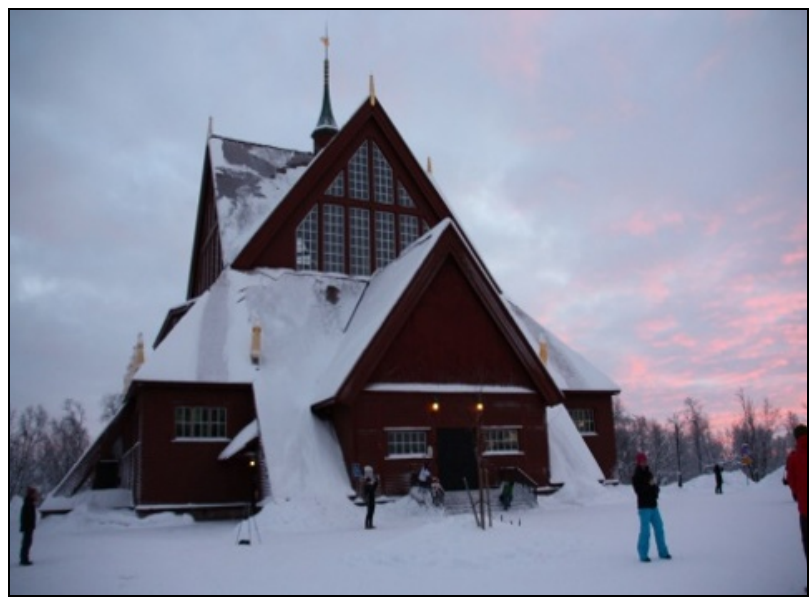

Fig. 2. An antique Evangelical Lutheran church (1909 - 1912) intended to be moved (photo by Mirosław Jankowiak).

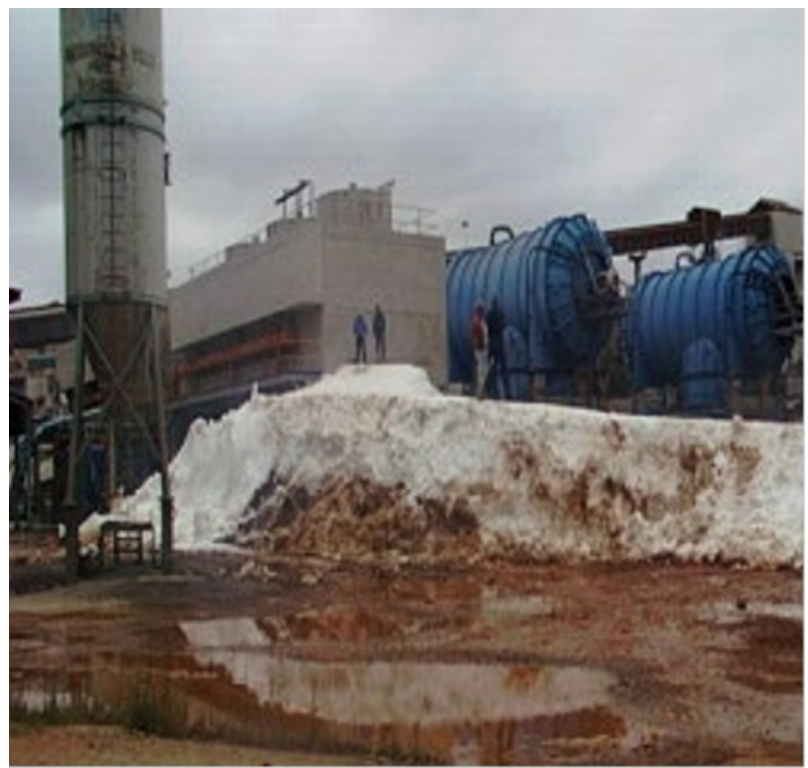

Fig. 3. The shaft site of the Mponeng mine. 
Among many points at the problems related to deep mining the first challenge that begins the sequence of problems to be solved is transporting mining crews on large distances is one. The Mponeng mine is $3800 \mathrm{~m}$ deep, and about $450 \mathrm{~km}$ long. Every day, approximately 4000 workers go down into workings. The first stage of the journey: the shaft, which allows descending to the depth of $2400 \mathrm{~m}$ in 6 minutes. The second stage of the ride: the cross-level shaft allowing descending to the depth of $3600 \mathrm{~m}$. The third stage is to reach the lowest level on foot or in a vehicle. The exploitation in these conditions is possible because of the utilisation of new, unique methods, technological processes, and technologies:

- air conditioning based on providing cold "on point", which is to ensure energy saving,

- a computer-controlled transportation system, allowing for security and efficiency,

- highly efficient fans capable of providing "air on request, at any moment",

- communication system relying on optic fibre for remote device operation at the depth of $3000 \mathrm{~m}$ (Fig. 4).

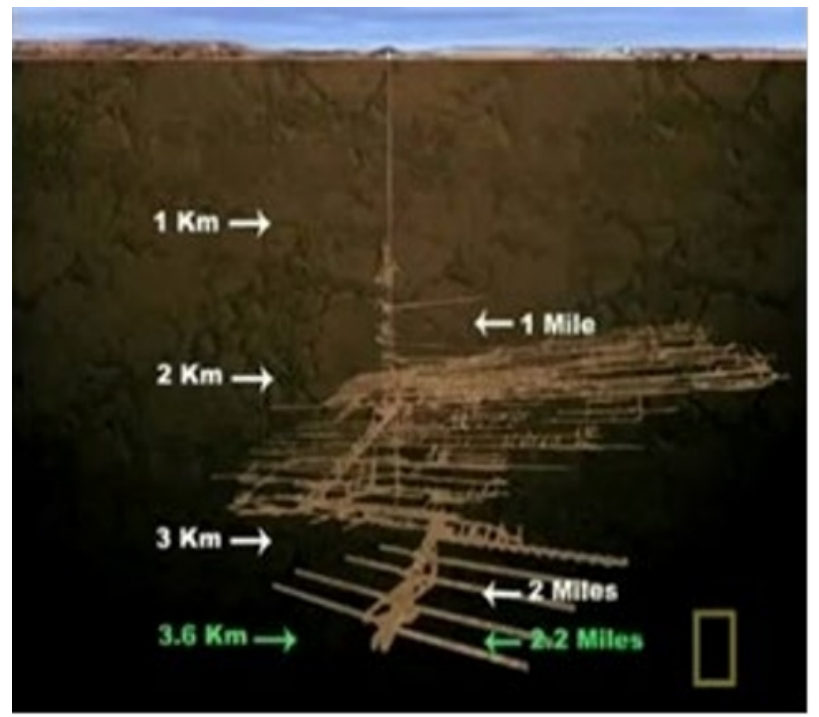

Fig. 4. The Mponeng Gold Mine in South Africa is the deepest gold mine on Earth, Discovery Communications.

The most interesting solution as a crucial for the Polish copper mining could be the air conditioning system. In the Mponeng mine, the original temperature of rocks in the faces reaches $60{ }^{\circ} \mathrm{C}$. To counter that, the air conditioning system uses crushed ice mixed with salt to transfer cold. The stations daily power is 6000 tons of ice. After being brought to underground, the cooling medium is located at the nodal points - constituting source of cold for "weather stations". The stream of air is controlled and distributed by the network of "weather stations" to the specified workplaces. It allows maintain the temperature of air on the acceptable level - less than $30{ }^{\circ} \mathrm{C}$.

Mining in Australia [4, 9, 10], similarly to South Africa, focuses strongly on solving the issue of high temperature. The Mt. Isa mine can serve as a fitting example (Fig. 5). There, people deal with the problem of high temperatures through the individual cooling methods, such as air-conditioned machine cabins and cooling clothing (vests). The work organisation rules, such as the pace of work, the time of work, adjustment of the shifts to the climatic conditions and respecting the break schedule also play a major role. Such organizational regulations that are complementary to the use of modern techniques and technologies require appropriate legal norms based on partnership deal between workers and entrepreneurs (Fig. 5).

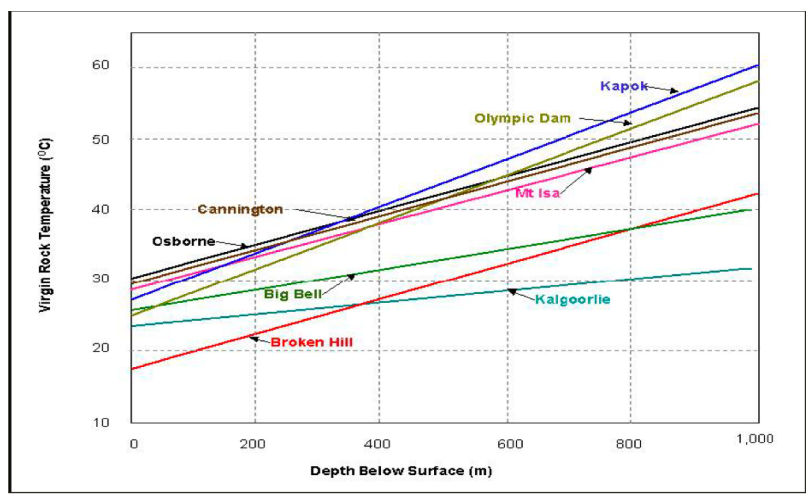

Fig. 5. The relation between depth and rock temperature on the example of selected Australian mines up to $1 \mathrm{~km}$ deep (from R. Podolski's private materials).

\section{The issues related to ventilation}

All topics pointed in introduction as problems in deep mining should be grouped by its relevance in long term planning. It seems beyond any discussion that vital meaning in deep mining of Polish copper mines should be always ventilation. The main task of a ventilation system is providing suitable environment for operation, safe to work in as well as possibly comfortable for the miners. For numerous reasons, it is a difficult task in KGHM mines. First of all, as a result of decades lasting exploitation it was formed very extensive network of workings where the flowing air quickly "absorbs" heat and water. Hot and humid air passing miles of ventilation roads contributes to emerge harsh climate condition. It is critical goal to simplify this network structure, improving air quality and increase energy efficiency of the installed devices (mainly fans). Second of all, the present ventilation structure has limited capacity, and with the deeper exploitation the amount and quality of fresh air delivered to working places in the mine must be optimized. Constant increase in the amount of air is costly solution and has its own quantitative limit. Taking into consideration today structure of the ventilation, this may significantly hinder further work. It is decisive scope to optimize distribution of air. The efficiency of the ventilation system depends also on constructing new shafts with increased air flow velocities (which would require novel of the law). The third issue are the natural hazards. Apart from the estimated and expected temperature increase along with depth, which creates the need for greater cold production, there is also the issue of gas hazards, ranging from gas-geodynamic events to getting closer to 
hydrocarbon deposits and the emanations of hydrogen sulphide as well as other sulphur compounds. The climate hazards call for the development of energy efficient cooling solutions, concerning cold production, as well as its distribution. There are many of such solutions around the world that could be utilised in KGHM mines after being appropriately adapted. This requires precise interdisciplinary cooperation between divisions obliged to manage ventilation structure planning and air conditioning. The gas hazards like $\mathrm{H}_{2} \mathrm{~S}$, which are increasing in importance despite their only recent emergence, they require thorough research and recognition, and the introduction of the procedures appropriate ensuring safe work in such conditions. Taking into consideration the experience got so far related to the variability of intensity in time function of gas emanation the regulations actually in force are not sufficient. The duty is to go far beyond the requirements of the regulations and it is very important, examining gradually this phenomenon, to describe the hazards qualitatively and quantitatively, as well as specify the ventilation requirements, especially in terms of its flexibility when it comes to delivering greater amounts of air to the endangered areas. The other challenge is to monitor air parameters, both in terms of its physical characteristics and its composition. The easier, digital acquisition of such data leads to the creation of extensive databases, transferring the burden of its importance to subsequent efficient analysis. The final challenge is to answer the question in which direction the ventilation network should develop in order to ensure the optimal working conditions.

\section{Issues concerning the natural environment}

There exist numerous issues concerning the natural environment requirements. The modern environmental standards require support of scientist of many fields and specialties in work on new projects. It is a result of a wide variety of factors influencing the environment, which are related to underground mines. Since the nature these factors depends on a particular mine, the already known research methods and instruments are often ineffective. According to the authors, one of the most important research areas resulting for the exploitation of the deep copper deposits will concern any actions aiming to minimise all emissions factors. In many cases it relates directly to the work safety of the mining crews, selection of the machinery appropriate to the geological and mining conditions, as well as the condition of the machinery or well designed and efficient ventilation system. From the perspective of environmental protection and emission reduction, it is important to:

- eliminate faulty machines with diesel engines,

- improve the machine maintenance system,

- introduce systems to stop all fuel and oil losses.

It is also vital to improve constantly the management of rock waste as well as water and sewage. The environmental permits' conditions are formulated on the basis and within the limits of the law, as are KGHM's actions in those areas. It does not mean, however, that young scientists should not be developing solutions that will be continuously reducing the influence of those systems on the natural environment. The separate topic is the post-flotation waste management as well as the possibility of its utilisation of the excavation voids. There are many ideas that emerge from time to time, such as turning the post-flotation waste into paste and filling the voids with it [11]. However, they still lack the complex project and technology capable of solving this problem.

\section{Conclusions}

Successful exploitation of Polish copper deposits depends a lot how smoothly and efficiently KGHM Polska Miedz S.A. will overcome all mentioned barriers in the GGP area, a region where new phenomena have emerged which can be defined as "not known beforehand and not easily addressed". Steady functioning operation of copper mining requires immediate start of research by the R\&D and scientific centers. Following foreign experiences authors express the conviction that this should be a form of group ventures for strengthening research teams to speed up the work. Because of specific geological and mining condition of GGP copper deposit not always it is possible to utilise ready solutions in such a way that the process of adapting it to the conditions of deep deposit exploitation would not disrupt the production process. This kind of approach will also be vital for the work safety. One can observe that in recent times the world mining industry (including KGHM) has been introducing periodically modern technical and technological changes in cycles mostly every ten years - so far. It allowed them to carry out effective mining activity. Such changes often are unique challenge for scientists and engineers and must occur constantly. Particularly, they imply activities causing innovation and improvement to prevent cited problems in areas such as:

a) in the areas of knowledge requiring strategic action:

- identification and precise categorisation of the hazards occurring along with the increase in depth,

- the assessment of the hazards caused by the cooccurrence of natural phenomena,

- periodic verification of the production processes,

b) in the areas of health protection:

- limiting the negative impact of the work environment,

- health problems in relation to cumulative harm factors, such as high temperature, humidity, dust, exhaust fumes, stress, and pressure,

- flexible work organisation, as function of an effective working time, the form of workers repose to assure acclimatization, refreshment,

c) in the areas of technical

- the ventilation structure's efficiency,

- optimisation of the mine's structural design,

- optimisation of the shaft transportation, 
- selection of the machinery appropriate for the deposit's parameters,

d) in the areas of safety

- research targeted to increase the effectiveness of rockburst forecasting, localization of zones bearing poison gases as well as zones prone to a rock and gases outburts,

- Application or modification of the rock mass assessment methods, different than known solutions such as Rock Mass Rating or Roof Fall Risk Index, in order to suit the needs of deep deposit exploitation,

e) in the areas of economy and legislation

- balanced in time investments for development works to create stable and reliable frame of ventilation and underground transport,

- cost reduction by optimization of excavation and development works restricted and limited by factor "mine built to the boundary of deposit",

- long-term planning in relation to the entire life mine structure, including the closing period a mine, and throughout its entire lifetime,

- $\quad$ stability and lucidity of the mining law, as well as in terms of accompanying acts related to environment, taxes and etc.,

f) impact on the natural environment

- the reduction of waste production

- the reduction of emission

- use of post-mining voids for depositing waste.

The above research areas are only some of those that should be developed in the near future by the teams of engineers and young scientists. For that reason, according to the authors, all efforts in this area are of crucial importance. It is vital to remember that today marks the begining of a new future.

\section{References}

1. Federal Mine Safety and Health Act of 1977, USA (1997)

2. Code of Federal Regulations, Title 30, USA

3. Handbook of Training in Mine and Recovery Operations 2014, Ontario Mine Rescue, Canada (2014)

4. Personal notes from technical visitations in Meikle and Henderson (USA), Goonyella and Mt. Isa (Australia), Mponeng (The Republic of South Africa) and Kiruna (Sweden)

5. Mine Health and Safety Act No. 74 of 2008, New South Wales (2008)

6. Guide to mineral and legislation and regulation in Sweden, Geological Survery of Sweden (2006)

7. J. Sjöberg, C. Dahnér, L. Malmgren, F. Perman, Forensic analysis of a rock burst event at the Kiirunavaara Mine - results and implications for the future (Itasca International Inc., Minneapolis, ISBN 978-0-9767577-2-6, 2011)
8. Mine Health and Safety Act (No. 96714 June 1996) No. 29 of 1996, The Republic of South Africa (1996)

9. Mining and Quarrying Safety and Health Regulation 2017, State of Queensland, SL No. 166 (remain necessary for the continued effective operation of the Mining and Quarrying Safety and Health Act (1999)

10. Materials included in "Management and prevention of heat stress, guidelines procedures", prepared for Goonyella and Mt. Isa mines (Australia)

11. S. Speczik, Mineral and Energy Economy Research Institute of the Polish Academy of Sciences, 91, 179-192 (2015) 